\title{
Carbofuran Induced Oxidative Stress in Rat Heart: Ameliorative Effect of Vitamin C
}

\author{
Sunil Kumar Jaiswal, ${ }^{1}$ Nikhat J. Siddiqi, ${ }^{2}$ and B. Sharma ${ }^{1}$ \\ ${ }^{1}$ Department of Biochemistry, University of Allahabad, Allahabad, Uttar Pradesh 211002, India \\ ${ }^{2}$ Department of Biochemistry, College of Science, King Saud University, P.O. Box 22452, Riyadh 11495, Saudi Arabia
}

Correspondence should be addressed to B. Sharma; sharmabi@yahoo.com

Received 10 October 2013; Accepted 7 November 2013

Academic Editors: A. Shukla, Z. S. Talas, and Y. Yoshida

Copyright (C) 2013 Sunil Kumar Jaiswal et al. This is an open access article distributed under the Creative Commons Attribution License, which permits unrestricted use, distribution, and reproduction in any medium, provided the original work is properly cited.

\begin{abstract}
The aim of this study was to evaluate the effect of carbofuran on the levels of certain biomarkers in heart of rat exposed to sublethal concentrations of pesticide for 30 days after each interval of $24 \mathrm{~h}$. The ameliorative effect of vitamin $\mathrm{C}$ by pretreatment of rats was also monitored. The results indicated that the activities of acetylcholinesterase and lactate dehydrogenase (LDH) decreased significantly in rat heart tissues, the extent of inhibition being concentration dependent. In contrast, the level of LDH increased in serum. The levels of malondialdehyde, total thiols, and glutathione were significantly elevated whereas the activities of antioxidant enzymes such as superoxide dismutase, catalase, and glutathione-S-transferase were remarkably decreased in rat heart tissues. The serum concentrations of cholesterol increased by 47 and $77 \%$ and high density lipids decreased by 35 and $64 \%$, respectively, due to exposure to 5 and $10 \% \mathrm{LD}_{50}$ of carbofuran. The prior treatment of rats with vitamin $\mathrm{C}\left(100 \mathrm{mg} \mathrm{kg}^{-1}\right.$ body weight) exerted significant ameliorative effect. The recovery was higher at low carbofuran concentration (5\%) tested. The results indicated that carbofuran induced oxidative stress and caused damage to cardiac tissues, which could be recovered by prior application of vitamin C.
\end{abstract}

\section{Introduction}

The pesticides have been widely used since past few decades to improve the yield of agricultural and forestry plant products. It is also used to protect the industry and household items. The use of pesticide is not specific which may lead to number of toxicological consequences to the environmental components [1]. The lower toxicity and lesser environmental persistence of organocarbamates have led their application more frequent than any other pesticide such as organophosphate $(\mathrm{OP})$, organochlorines $(\mathrm{OCl})$. The $\mathrm{OP}$ pesticides inactivate acetylcholinesterase (AChE) via irreversible ester bond formation with hydroxyl group of serine residue present at the active site of enzyme. AChE is responsible for hydrolyzing the neurotransmitter, acetylcholine (ACh), in central as well as in peripheral nervous systems [2]. The mechanism of action of organochlorine pesticides such as lindane ( $\gamma$-hexachlorocyclohexane) is hyperexcitability [3] by both stimulating the synaptic transmission and suppressing the GABAactivated chloride current by interacting with the receptor
GABA-chloride channel complex [4]. The organocarbamate pesticides cause reversible inhibition of AChE by carbamylation of serine residue of AChE. The inhibition is therefore short lived. Thus, it causes relatively low toxicity as compared to $\mathrm{OP}$ and organochlorine pesticides [5].

Carbofuran $\left(\mathrm{C}_{12} \mathrm{H}_{15} \mathrm{NO}_{3}\right.$; 2,3-dihydro-2,2-dimethyl-7-benzofuranol methylcarbamate), commonly known as furadan, is a broad spectrum carbamate pesticide which is used in various farm practices in order to increase crop productivity. Due to its broad spectrum action and short half-life in the environment, it is also used as an insecticide, nematicide, and acaricide $[6,7]$. The presence of carbofuran is also reported in the nontarget mammalian systems such as maternal plasma, umbilical cord, and blood of African-American women and new born babies, respectively [8]. It has been shown to be generally accumulated in the fat depots and to exert adverse effects on different vital organs such as brain, liver, skeletal muscles, and heart $[5,6,9]$. The neuronal injury of mammalian system due to carbofuran is due to the establishment of oxidative stress. Rai et al. (2011) reported that 
oral dose administration of carbofuran causes neuronal injury which was mitigated by the administration of aqueous extract of Cynodon dactylon and vitamin C [10]. Yang and Dettbarn established the correlation between accumulation of acetylcholine and the extent of lipid peroxidation [11].

The underlying mechanism of pesticide toxicity relies on generation of oxidative stress [2]. The administration of carbofuran has been found to induce reactive oxygen and nitrogen species in skeletal muscles [1]. Reactive oxygen species and/or free radicals are responsible for the peroxidation of membrane phospholipids which disrupt the normal function of lipid bilayer and help develop several pathological conditions. The alterations in the membrane lipids can also influence the function of membrane-bound ion-motive ATPases such as $\mathrm{Na}^{+}-\mathrm{K}^{+}$-ATPase and $\mathrm{Ca}^{2+}$-ATPase [12-14].

Padilla et al. reported that single sublethal doses of seven $\mathrm{N}$-methylcarbamate pesticides (carbaryl, carbofuran, formetanate, methiocarb, methomyl, oxamyl, or propoxur) caused AChE inhibition in the brain and red blood cells which recovered within $24 \mathrm{~h}$ [15] after the withdrawal of the pesticide. The earlier experimental results from our and other laboratories have established that carbofuran treatment was able to inhibit AChE activity and also to produce oxidative stress by enhancing level of malondialdehyde (MDA) and significantly altering the activities of antioxidant enzymes such as superoxide dismutase (SOD), catalase, and glutathione-Stransferase (GST) in liver [5], brain [10, 16], kidney [17], and erythrocytes $[9,18]$. These studies suggested that the intensity of the inhibition of AChE showed positive correlation with the level of MDA.

The mechanism of action of antioxidant compounds follows one or more than one type of mechanisms to reduce the impact of the oxidative stress induced in living systems, scavenge free radicals by forming complexes with pro-oxidants and thereby quenching the free radical species due to the exposure to any physical or chemical agents. The biological system comprises two types of antioxidants, nonenzymatic molecules like glutathione and vitamins (C, D, and E) and the enzymatic indices such as SOD, catalase, and GST [19]. Ascorbic acid (vitamin C) is a nonenzymatic antioxidant which exhibits the property to potentially scavenge free radicals from extracellular fluids thereby offering protection of membrane lipid bilayer from peroxidative damage $[9,20]$.

Though it has been reported that the rat heart has a limited antioxidant defense system hence it is more prone to the oxidative damage by OP pesticides [21], there is no information available to indicate the induction of oxidative stress due to introduction of repeated doses of subacute concentrations of carbofuran as well as mitigation of the pesticide induced toxicity by vitamin C. Keeping this fact in view, the present study was envisaged by treating the rats with two subacute concentrations ( $5 \%$ and $10 \% \mathrm{LD}_{50}$ value) of carbofuran for a longer period (up to 30 days) at the interval of $24 \mathrm{~h}$. The levels of oxidative as well as antioxidative indices were monitored in the heart of the animal. The influence of pretreatment of rats with vitamin $\mathrm{C}$ onto the impact of carbofuran on the above oxidative biomarkers in heart of the rats was also evaluated.

\section{Materials and Methods}

2.1. Chemicals. Carbofuran (2,3-dihydro-2,2-dimethyl-7-benzofuranyl N-methylcarbamate) technical grade $99.6 \%$ pure in powered form was a kind gift from Rallis India Limited, Bangalore, India. Edible groundnut oil was purchased from the local market. All other chemicals used were of analytical grade.

2.2. Animals. Thirty male Wister rats weighing 100 to $120 \mathrm{~g}$ and age of 7 to 8 weeks were purchased from Central Drug Research Institute (CDRI), Lucknow, India. All animals were housed in polypropylene cage under ambient environmental conditions. Animals were fed standard pellet diet (Dayal Industries Limited, Lucknow, India) along with water ad libidum. The protocols for maintenance, care, and treatment of animals were followed as per the provisions laid down by the Institutional Animal Ethical Committee.

2.3. Experimental Design. Thirty male Wister rats were divided into six groups and each group contained five animals.

Control. The group received only $0.5 \mathrm{~mL}$ groundnut oil orally, 30 days at the interval of $24 \mathrm{~h}$.

$5 \%$ Carbofuran (5\% CF). The group received $5 \%$ of $\mathrm{LD}_{50}$, that is, $0.4 \mathrm{mg}$ carbofuran $\mathrm{kg}^{-1}$ body weight in $0.5 \mathrm{~mL}$ ground nut oil orally, 30 days at the interval of $24 \mathrm{~h}$.

$10 \%$ Carbofuran (10\% CF). The group received $10 \%$ of $\mathrm{LD}_{50}$, that is, $0.8 \mathrm{mg}$ carbofuran $\mathrm{kg}^{-1}$ body weight in $0.5 \mathrm{~mL}$ ground nut oil orally, 30 days at the interval of $24 \mathrm{~h}$.

Vitamin C (Vit C). $100 \mathrm{mg} \mathrm{kg}^{-1}$ body weight in $0.5 \mathrm{~mL}$ double distilled water orally, 30 days at the interval of $24 \mathrm{~h}$.

Vitamin C + 5\% Carbofuran (Vit C + 5\% CF). $100 \mathrm{mg} \mathrm{kg}^{-1}$ body weight of vitamin $\mathrm{C}$ was given just 30 minutes before $5 \% \mathrm{LD}_{50}$ of carbofuran treatment, 30 days at the interval of $24 \mathrm{~h}$.

Vitamin C + 10\% Carbofuran (Vit C + 10\% CF). $100 \mathrm{mg} \mathrm{kg}^{-1}$ body weight of vitamin $\mathrm{C}$ was given just 30 minutes before $10 \% \mathrm{LD}_{50}$ of carbofuran treatment, 30 days at the interval of $24 \mathrm{~h}$.

At the end of the treatment, all animals were anaesthetized with mild chloroform and sacrificed.

2.4. Preparation of Tissue Homogenates for Assay of AChE Activity. The hearts from the sacrificed animals were removed and washed with ice-cold saline $(0.9 \%, \mathrm{NaCl})$, blotted dry, and weighed. For AChE activity assay, heart tissues were homogenized $(10 \%, \mathrm{w} / \mathrm{v})$ in $50 \mathrm{mM}$ phosphate buffer, $\mathrm{pH} 8.0$ containing $0.2 \%$ Triton $\mathrm{X}-100$ at $4^{\circ} \mathrm{C}$ using Remi homogenizer pestle coated with Teflon. The homogenate was kept in the capped centrifuge tubes for $30 \mathrm{~min}$ at $4^{\circ} \mathrm{C}$ with intermittent gentle shaking to solubilize the membrane-bound enzyme and then centrifuged at $10,000 \times \mathrm{g}$ for $30 \mathrm{~min}$ at $4^{\circ} \mathrm{C}$. The supernatant was collected in precooled eppendorf tubes and 
the pellet was discarded. This preparation was used for the assay of AChE activity as well as protein estimation.

2.5. Preparation of Tissue Homogenates for Activity Assay of Antioxidant Enzymes and Estimation of Biomolecules. The $10 \%(\mathrm{w} / \mathrm{v})$ homogenates of heart tissues were prepared in $0.25 \mathrm{M}$ sucrose solution and centrifuged at $9000 \times \mathrm{g}$ for $30 \mathrm{~min}$ at $4-6^{\circ} \mathrm{C}$. The supernatants were separated by gentle decantation and used for assay of antioxidant enzymes and estimations of the levels of certain biomolecules.

2.6. Preparation of Serum from Rat Blood. About $5 \mathrm{~mL}$ blood was collected from each animal in sterile centrifuged tube. The coagulated blood was centrifuged at $1000 \times \mathrm{g}$ at $4^{\circ} \mathrm{C}$ for $10 \mathrm{~min}$ and the serum was collected as supernatant.

2.7. Assay of AChE Activity in the Tissue Homogenates. The activity of acetylcholinesterase (AChE, E.C. 3.1.1.7) was assayed by the method of Ellman et al. [22]. The reaction mixture $(3 \mathrm{~mL})$ in quartz cuvette $(1 \mathrm{~cm}$ light path length) contained $0.5 \mathrm{mM}$ acetylthiocholine iodide (ATI), $0.5 \mathrm{mM}$ DTNB [5, 5'-dithiobis-(nitrobenzoic acid)], and $50 \mathrm{mM}$ phosphate buffer, $\mathrm{pH}$ 7.6. The change in absorbance was measured at $412 \mathrm{~nm}$ for $3 \mathrm{~min}$. The specific activity of enzyme was calculated and presented as $\mathrm{IU} \mathrm{mg}^{-1}$ protein using molar absorbance, $13.6 \times 10^{3} \mathrm{M}^{-1} \mathrm{~cm}^{-1}$. Assays were performed on UV-Visible double beam spectrophotometer (Thermo Scientific). The reaction mixture without enzyme protein served as a control in this assay.

2.8. Lactate Dehydrogenase (LDH) Activity Assay. The activity of lactate dehydrogenase (LDH, E.C. 1.1.1.27) was assayed by the method of Horecker and Kornberg [23] in serum and the cell-free extracts of heart. The reaction was performed in quartz cuvette $(1 \mathrm{~cm}$ light path length). The total reaction mixture $(3 \mathrm{~mL})$ contained $1 \mathrm{~mL} 0.2 \mathrm{M}$ Tris- $\mathrm{HCl}$ buffer, $\mathrm{pH}$ 7.4, $0.15 \mathrm{~mL} 0.1 \mathrm{M} \mathrm{KCl}, 0.15 \mathrm{~mL} 50 \mathrm{mM}$ sodium pyruvate, $0.20 \mathrm{~mL}$ $2.4 \mathrm{mM} \mathrm{NADH}$, and suitably diluted enzyme protein. The enzyme activity was monitored as decrease in the absorbance at $340 \mathrm{~nm}$ for $3 \mathrm{~min}$. The reaction mixture without enzyme protein served as a control in this assay system.

2.9. Estimation of Serum Lipids. The contents of serum total cholesterol (TC) and high density lipoprotein (HDL) were measured spectrophotometrically at $560 \mathrm{~nm}$ by the method of Zlatkis et al. [24]. Cholesterol was used as standard to determine the value of unknown sample. For HDL measurement the supernatant of serum treated with phosphotungstic acid and $\mathrm{MgCl}_{2}$ [25] was used; and the HDL content was determined according to the method of Zlatkis et al. [24].

2.10. Estimation of TBARS Levels. Lipid peroxidation was measured in the cytosolic fraction of heart tissues by following the method of Niehaus and Samuelsson and the results were expressed as nmol $\mathrm{MDA} / \mathrm{mg}$ protein using the extinction coefficient of $1.56 \times 10^{5} \mathrm{M}^{-1} \mathrm{~cm}^{-1}$ [26]

2.11. Estimation of the Activities of Antioxidant Enzymes. The activity of superoxide dismutase (SOD, E.C. 1.15.1.1) was measured by using the method of S. Marklund and G. Marklund [27]. It is a spectrophotometric measurement of optical density of coloured complex involving pyrogallol auto-oxidation at $412 \mathrm{~nm}$ for $3 \mathrm{~min}$ at the interval of $30 \mathrm{~s}$ with or without the enzyme protein. One unit of the enzyme activity was expressed as 50\% inhibition of auto-oxidation of pyrogallol per min.

The catalase (CAT, E.C. 1.11.1.6) activity was measured according to the method of Beers and Sizer [28] by measuring the decrease in the absorbance for $\mathrm{H}_{2} \mathrm{O}_{2}$ consumption at $240 \mathrm{~nm}$ at the interval of $30 \mathrm{~s}$ for $3 \mathrm{~min}$. One unit of CAT activity was defined as micromoles of $\mathrm{H}_{2} \mathrm{O}_{2}$ decomposed per min using molar absorbance of $\mathrm{H}_{2} \mathrm{O}_{2}\left(43.6 \mathrm{M}^{-1} \mathrm{~cm}^{-1}\right)$.

The activity of glutathione-S-transferase (GST, E.C. 2.5. 1.18) was measured according to the method of Habig et al. [29]. The change in absorbance was recorded spectrophotometrically at $340 \mathrm{~nm}$ for $3 \mathrm{~min}$ at the interval of $30 \mathrm{~s}$ and the results were expressed as $\mu$ mole $\mathrm{mL}^{-1} \mathrm{~min}^{-1} \mathrm{mg}^{-1}$ protein.

2.12. Determination of the Levels of Nonenzymatic Antioxidants. The total thiol content in the heart tissues was determined by the method of Ellman et al. [22] and modified by Sedlak and Lindsay [30]. The intensity of yellow colour was measured at $412 \mathrm{~nm}$. In $2.0 \mathrm{~mL}$ micro centrifuge tube the reaction mixture $(1 \mathrm{~mL})$ contained $105 \mu \mathrm{L} 0.2 \mathrm{M}$ Tris$\mathrm{HCl}$ buffer ( $\mathrm{pH}$ 8.2), $20 \mu \mathrm{L} 0.01 \mathrm{M}$ DTNB, $825 \mu \mathrm{L}$ absolute methanol, and $50 \mu \mathrm{L}$ of heart homogenate; it was mixed and wait for $15 \mathrm{~min}$ with intermittent shaking and then centrifuged at $800 \times \mathrm{g}$ for $15 \mathrm{~min}$. The absorbance of the supernatant was recorded. The results were expressed as $\mu \mathrm{g} \mathrm{mg}^{-1}$ protein.

The GSH content in heart tissues was determined by the method of Ellman et al. [22]. Briefly, the $250 \mu \mathrm{L}$ deproteinized supernatant of heart homogenate was mixed with $100 \mu \mathrm{L}$ of $6 \mathrm{mM}$ DTNB, $300 \mu \mathrm{L}$ of $200 \mathrm{mM}$ phosphate buffer $(\mathrm{pH}$ 8.0 ), and $50 \mu \mathrm{L}$ of $300 \mathrm{mM} \mathrm{NaOH}$. The absorbance of the reaction mixture was measured at $412 \mathrm{~nm}$. All the values were expressed as $\mu \mathrm{gm} \mathrm{mg}^{-1}$ protein.

2.13. Determination of Total Protein in the Heart and Serum. The protein content present in different samples was measured according to the method of Lowry et al. [31] using BSA as a standard.

2.14. Statistical Analysis. Data are presented as mean \pm standard deviation using Graph Pad Prism version 5.01 for Windows, Graph Pad Software, San Diego, California, USA. Data were analyzed using one way analysis of variance (ANOVA). Different groups were compared using Bonferroni's Multiple Comparison Test and considered significant at $P \leq 0.05$.

\section{Results}

3.1. Effect of Carbofuran and Vitamin $C$ on the Activity of $A C h E$ in the Heart of Rat. AChE catalyzes the hydrolysis of a neurotransmitter acetylcholine thereby facilitating the nerve impulse transmission. Carbofuran causes reversible inhibition of this enzyme. The effect of carbofuran was studied by 
TABLE 1: Summary of the results showing the effect of carbofuran on the activity of AChE in the heart of Wistar rat as presented in Figure 1.

\begin{tabular}{lccccc}
\hline & \multicolumn{5}{c}{ Activity of acetylcholinesterase (AChE; IU mg ${ }^{-1}$ protein) } \\
Control & $5 \% \mathrm{CF}$ & $10 \% \mathrm{CF}$ & Vit. C & Vit. C $+5 \%$ CF & Vit. C + 10\% CF \\
\hline 45.06 & $36.69^{* *}(-20 \%)$ & $18.88^{* * *}(-60 \%)$ & $46.18^{\text {ns }}$ & $40.15^{\text {ns }}$ & $36.86^{*}$ \\
\hline
\end{tabular}

The (-) sign shows decrease in the AChE activity. The values are mean \pm SD of five independent experiments. The procedure for estimation of AChE activity was the same as mentioned in Section 2. ns: nonsignificant. $*, * *$, and $* * *$ indicate the $P$ values significance at $<0.05,<0.01$, and $<0.001$, respectively. ns: nonsignificant at $P>0.05$ as compared to control.

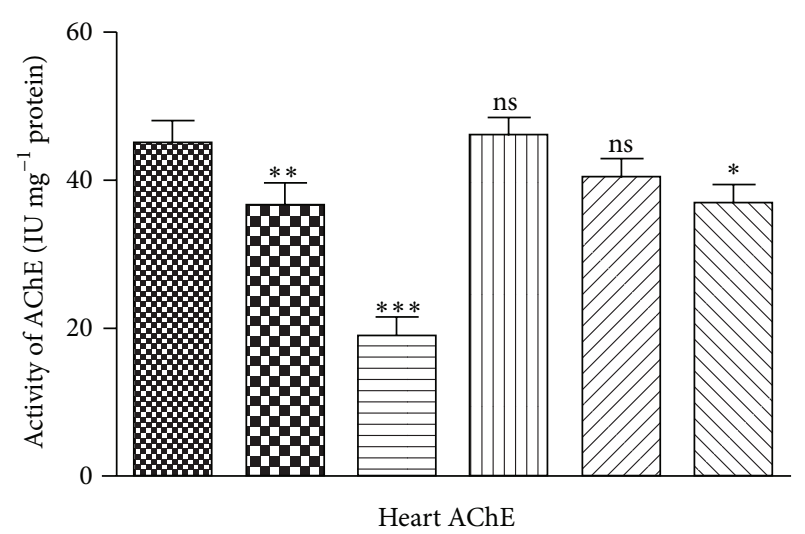

$$
\begin{aligned}
& \text { B. Control } \\
& \text { 므므 } 5 \% \mathrm{CF} \\
& 10 \% \mathrm{CF}
\end{aligned}
$$

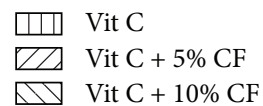

FIGURE 1: Effect of carbofuran and vitamin $\mathrm{C}$ on the activity of $\mathrm{AChE}$ in the rat heart. The procedures for the administration of carbofuran and pretreatment with vitamin $\mathrm{C}$ as well as assay of AChE activity were the same as mentioned in Section 2. The unit of enzyme activity was expressed as IU $\mathrm{mg}^{-1}$ protein. The data represent mean \pm SD of 5 independent experiments. ${ }^{*},{ }^{* *}$, and ${ }^{* * *}$ indicate the $P$ values significance at $<0.05,<0.01$, and $<0.001$, respectively. $\mathrm{ns}=$ nonsignificant at $P>0.05$ as compared to the control group.

oral treatment of rats up to 30 days at the interval of $24 \mathrm{~h}$ with 5 and $10 \% \mathrm{LD}_{50}$ of carbofuran. Two groups of rats received pretreatment with vitamin $C$ followed by exposure to two different concentrations of carbofuran. AChE activity was estimated in the heart tissues of treated rats. The results presented in Figure 1 indicated significant inhibition of the enzyme by 5 and $10 \% \mathrm{LD}_{50}$ of carbofuran, the extent of inhibition being 20 and $60 \%$, respectively. It was concentration dependent. The pretreatment of rats with vitamin $C$ resulted in significant recovery of the cardiac AChE activity, the extent of recovery being higher at lower carbofuran concentration. These results have been summarized in Table 1.

\subsection{Effect of Carbofuran on the Activity of LDH in Heart} of Rat. LDH catalyzes a reversible terminal biochemical reaction of conversion of pyruvic acid into lactic acid in anaerobic glycolysis. LDH is not the direct target of action of carbofuran. In order to assess whether carbofuran exerts any effect on the energy metabolism, in the present study the activity of LDH was estimated in the heart tissues of rats exposed to 5 and $10 \% \mathrm{LD}_{50}$ of carbofuran for 30 days at
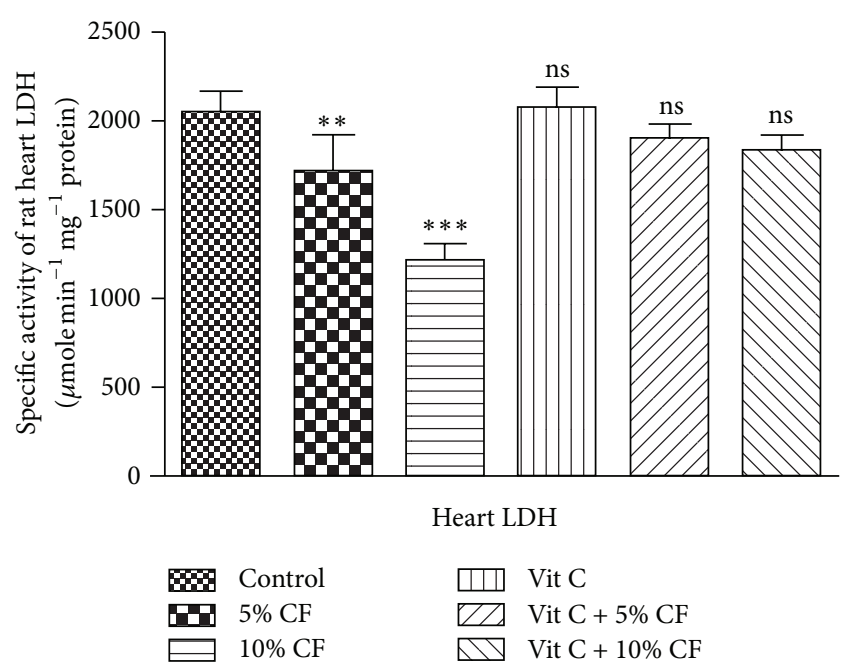

FIgURE 2: Effect of carbofuran and vitamin $\mathrm{C}$ on the activity of rat heart LDH. The procedure for estimation of LDH activity was the same as the one mentioned in Section 2. The unit of enzyme activity was expressed as $\mu$ moles $\mathrm{min}^{-1} \mathrm{mg}^{-1}$ protein. The data represent mean \pm SD of 5 independent experiments. ${ }^{* *}$ and ${ }^{* * *}$ indicate the $P$ values significance at $<0.01$ and $<0.001$, respectively. ns $=$ nonsignificant at $P>0.05$ as compared to the control group.

the interval of $24 \mathrm{~h}$. The results presented in Figure 2 demonstrated that the enzyme activity was significantly inhibited in the heart tissues, the values of inhibition being 16 and $41 \%$, respectively, at 5 and $10 \% \mathrm{LD}_{50}$ of carbofuran. The extent of inhibition was concentration dependent. The groups which received pretreatment of rats with vitamin $C\left(100 \mathrm{mg} \mathrm{kg}^{-1}\right.$ body weight) followed by exposure to above concentrations of the pesticide displayed protection from carbofuran mediated toxicity to the significant levels, the extent of protection being higher at lower carbofuran concentration tested. These results have been summarized in Table 2 .

\subsection{Effect of Carbofuran on the Activity of $L D H$ in the Serum} of Rat. In order to evaluate the pathophysiological effect of carbofuran on the rat heart tissues, the activity of $\mathrm{LDH}$ was monitored in the serum of the animal treated with the pesticide as mentioned in Section 2. The results presented in Figure 3 indicated that the pesticide treatment caused significant elevation in the level of LDH in serum, the extent of increase being 29.72 and $66.31 \%$, respectively, at 5 and $10 \%$ $\mathrm{LD}_{50}$ of carbofuran. Upon preatmebnt of rats with vitamin $\mathrm{C}$ exhibited significant recovery in the enzyme activity as 
TABLE 2: Summary of the results showing the effect of carbofuran on the activity of LDH in the heart of Wistar rat as presented in Figure 2.

\begin{tabular}{lccccc}
\hline \multicolumn{5}{c}{ Activity of LDH $\left(\mu\right.$ moles $\mathrm{min}^{-1} \mathrm{mg}^{-1}$ protein $)$} \\
Control & $5 \% \mathrm{CF}$ & $10 \% \mathrm{CF}$ & Vit. C & Vit. C $+5 \%$ CF & Vit. C $+10 \%$ CF \\
\hline 2069 & $1739^{* *}(-15.94 \%)$ & $1230^{* * *}(-40.5 \%)$ & $2085^{\text {ns }}$ & $1916^{\text {ns }}$ & $1849^{\text {ns }}$ \\
\hline
\end{tabular}

The (-) sign shows decrease in the AChE activity. The values are mean \pm SD of five independent experiments. The procedure for estimation of AchE activity was the same as mentioned in Section 2. ns: nonsignificant. $* *$ and $* * *$ indicate the $P$ values significance at $<0.01$ and $<0.001$, respectively. ns: nonsignificant at $P>0.05$ as compared to control.

TABLE 3: Summary of the results showing the effect of carbofuran on the activity of LDH in serum of Wistar rat as presented in Figure 3.

\begin{tabular}{lccccc}
\hline & & \multicolumn{2}{c}{ Activity of LDH $\left(\mu\right.$ moles $\mathrm{min}^{-1} \mathrm{mg}^{-1}$ protein $)$} \\
Control & $5 \%$ CF & $10 \%$ CF & Vit. C & Vit. C + 5\% CF & Vit. C $+10 \%$ CF \\
\hline 3.740 & $4.890^{*}(+29.72 \%)$ & $6.220^{* * *}(+66.31 \%)$ & $3.375^{\text {ns }}$ & $3.865^{\text {ns }}$ & $4.165^{\text {ns }}$ \\
\hline
\end{tabular}

The $(+)$ sign shows increase in the LDH activity. The values are mean \pm SD of five independent experiments. The procedure for estimation of LDH activity was the same as mentioned in Section 2. ns: nonsignificant. $* *$ and $* * *$ indicate the $P$ values significance at $<0.05$ and $<0.001$, respectively. ns: nonsignificant at $P>0.05$ as compared to control.

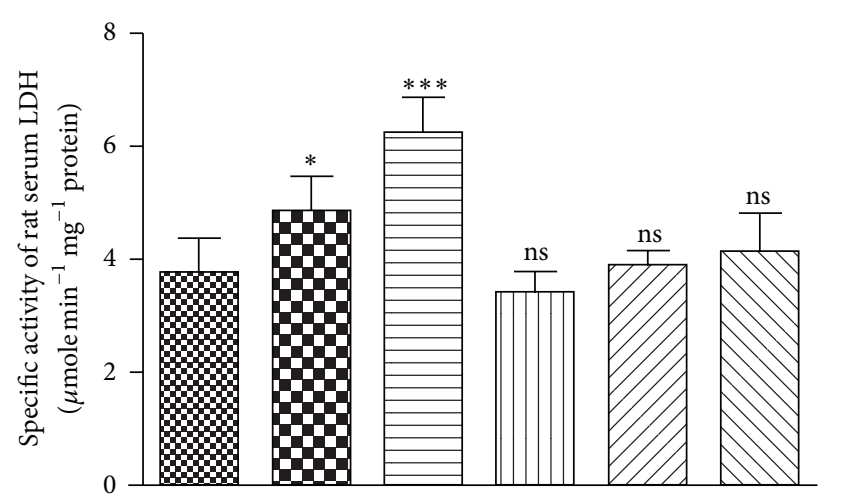

Serum LDH

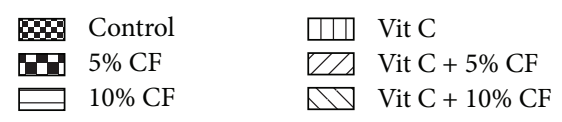

FIGURE 3: Effect of carbofuran and vitamin $\mathrm{C}$ on the activity of $\mathrm{LDH}$ in the serum from rat. The procedure for estimation of $\mathrm{LDH}$ activity was the same as the one mentioned in Section 2. The unit of enzyme activity was expressed as $\mu$ moles $\mathrm{min}^{-1} \mathrm{mg}^{-1}$ protein. The data represent mean \pm SD of 5 independent experiments. ${ }^{* * *}$ indicates the $P$ values significance at $<0.001$. ns $=$ nonsignificant at $P>0.05)$ as compared to the control group.

the activity values were recorded to be close to that of control. These results have been summarized in Table 3 .

\subsection{Effect of Carbofuran on the Level of Malonaldehyde} (MDA), Total Thiol, and Reduced Glutathione (GSH) in Rat Heart Tissues. The levels of MDA, total thiol, and GSH in the heart tissues were determined in order to assess the generation of free radicals and oxidative stress in heart due to carbofuran treatment. The results presented in Table 4 indicated that even the low concentration of carbofuran, that is, $5 \% \mathrm{LD}_{50}$, was able to significantly increase the levels of MDA, total thiols, and GSH by $30.87,37.9$, and $63 \%$, respectively. Upon two times increase in the concentration of carbofuran, that is, $10 \% \mathrm{LD}_{50}$, these values were further enhanced to 65,156 , and $263 \%$, respectively. The data indicated that the effect of carbofuran is concentration dependent. When the experimental animals were pretreated with vitamin $\mathrm{C}$ followed by exposure to carbofuran, the levels of MDA, total thiols, and GSH were observed close to that of control showing significant protection from the pesticide's intoxication in rat heart (Table 4).

3.5. Effect of Carbofuran on the Activities of Antioxidant Enzymes (SOD, Catalase and GST) in Rat Heart Tissues. Since it was observed in previous experiments that carbofuran treatment at subacute concentrations generated oxidative stress and increased the levels of antioxidative nonenzymatic biomolecules, the endeavour was made to evaluate the effect of the pesticide on the levels of the activities of enzymatic antioxidative indices. The activities of SOD, catalase, and GST were measured in the pesticide treated tissues as mentioned in Section 2. The results presented in Table 5 revealed that carbofuran even at low concentration, that is, $5 \% \mathrm{LD}_{50}$ significantly influenced the activities of these enzymes, the level of inhibition being $18,22.7$, and $13 \%$, respectively. When the concentration of pesticide was raised to twofolds, that is, $\left(10 \% \mathrm{LD}_{50}\right)$, further higher level of inhibition in the activities of these enzymes was recorded, the extent of inhibition being 37 , 35, and 36\%, respectively, for SOD, catalase, and GST. The activities of these enzymes were also monitored in the heart tissues of the rats pretreated with vitamin $C$. The results presented in Table 5 demonstrated that the introduction of vitamin $C$ reflected significant ameliorative effects as the values of these enzymes were observed to be close to that of the control. The extent of recovery was more at lower concentration of the pesticide (Table 5).

3.6. Effect of Carbofuran on the Levels of Total Cholesterol and HDL in Rat Serum. Keeping in view the importance of the total cholesterol and HDL for the assessment of the pathophysiological status of heart, the experiments were conducted to estimate their levels in the serum of rat treated with two subacute concentrations of carbofuran as shown in Section 2. The results presented in Table 6 reflected 
TABLE 4: Effect of carbofuran and vitamin C on level of MDA, total thiol, and GSH in heart tissues.

\begin{tabular}{lccc}
\hline & Level of $\mathrm{MDA}^{\mathrm{a}}$ & Level of total thiol $^{\mathrm{b}}$ & Level of GSH $^{\mathrm{b}}$ \\
\hline Control & $2.91 \pm 0.33$ & $7.78 \pm 0.90$ & $1.79 \pm 0.21$ \\
$5 \%$ CF & $3.802 \pm 0.1607^{* *}(+30.87 \%)$ & $10.74 \pm 1.052^{* *}(+37.9 \%)$ & $2.93 \pm 0.37^{* *}(+63 \%)$ \\
$10 \%$ CF & $4.89 \pm 0.46^{* * *}(+65 \%)$ & $19.97 \pm 1.78^{* * *}(+156 \%)$ & $6.51 \pm 0.63^{* * *}(+263 \%)$ \\
Vit C & $2.81 \pm 0.28^{\mathrm{ns}}$ & $7.65 \pm 1.25^{\mathrm{ns}}$ & $1.75 \pm 0.29^{\mathrm{ns}}$ \\
Vit C $+5 \%$ CF & $2.99 \pm 0.35^{\mathrm{ns}}$ & $8.51 \pm 0.99^{\mathrm{ns}}$ & $2.23 \pm 0.441^{\mathrm{ns}}$ \\
Vit C $+10 \%$ CF & $3.46 \pm 0.17^{\mathrm{ns}}$ & $9.31 \pm 0.88^{\mathrm{ns}}$ & $2.56 \pm 0.26^{\mathrm{ns}}$ \\
\hline
\end{tabular}

a (nmoles of MDA mg ${ }^{-1}$ protein), ${ }^{b}\left(\mu \mathrm{g} \mathrm{mg}^{-1}\right.$ protein); the (+) sign shows increase in the MDA and GSH contents. The values are mean \pm SD of five independent experiments. The procedure for estimation of MDA and GSH was the same as mentioned in Section 2. ns: nonsignificant. $* *$ and $* * *$ indicate the $P$ values significance at $<0.01$ and $<0.001$, respectively. ns: nonsignificant at $P>0.05$ as compared to control.

TABLE 5: Effect of carbofuran and vitamin C on antioxidant enzymes in heart tissues.

\begin{tabular}{|c|c|c|c|}
\hline Activity of antioxidative enzymes & Activity of SOD ${ }^{\mathrm{a}}$ & Activity of catalase $^{\mathrm{a}}$ & Activity of GST ${ }^{b}$ \\
\hline Control & $7.49 \pm 0.69$ & $1.54 \pm 0.18$ & $111.3 \pm 4.65$ \\
\hline $5 \% \mathrm{CF}$ & $6.14 \pm 0.51^{*}(-18.1 \%)$ & $1.19 \pm 0.08^{* *}(-22.7 \%)$ & $96.75 \pm 5.56^{*}(-13 \%)$ \\
\hline $10 \% \mathrm{CF}$ & $4.72 \pm 0.69^{* * *}(-36.98 \%)$ & $0.9950 \pm 0.08^{* * *}(-35.3 \%)$ & $71.00 \pm 8.33^{* * *}(-36 \%)$ \\
\hline Vit C & $7.79 \pm 0.614^{\mathrm{ns}}$ & $1.59 \pm 0.07^{\mathrm{ns}}$ & $112.5 \pm 4.041^{\mathrm{ns}}$ \\
\hline Vit $C+5 \% \mathrm{CF}$ & $7.37 \pm 0.72^{\mathrm{ns}}$ & $1.33 \pm 0.12^{\mathrm{ns}}$ & $103.0 \pm 6.78^{\mathrm{ns}}$ \\
\hline Vit $C+10 \% \mathrm{CF}$ & $5.89 \pm 0.841^{\mathrm{ns}}$ & $1.28 \pm 0.11^{\mathrm{ns}}$ & $97.75 \pm 5.25^{\mathrm{ns}}$ \\
\hline
\end{tabular}

${ }^{\mathrm{a}} \mathrm{IU} \mathrm{mg}{ }^{-1}$ protein, ${ }^{\mathrm{b}} \mu \mathrm{mole} \mathrm{mL}^{-1} \mathrm{~min}^{-1} \mathrm{mg}^{-1}$ protein; the (-) sign shows decrease in the activity. The values are mean \pm SD of five independent experiments. The procedures for estimation of the activities of the enzymes were as mentioned in Section $2 . *, * *$, and $* * *$ indicate the $P$ values significance at $<0.05$, $<0.01$, and $<0.001$, respectively. ns: nonsignificant at $P>0.05$ as compared to control.

TABLE 6: Effect of carbofuran and vitamin $\mathrm{C}$ on level of total cholesterol and HDL in serum.

\begin{tabular}{|c|c|c|c|c|c|c|}
\hline Level of lipids & Control & $5 \% \mathrm{CF}$ & $10 \% \mathrm{CF}$ & Vit. C & Vit. $C+5 \%$ CF & Vit. $\mathrm{C}+10 \% \mathrm{CF}$ \\
\hline Total cholesterol $^{\mathrm{a}}$ & $189.7 \pm 12.36$ & $278.7 \pm 13.28^{* * *}(+47 \%)$ & $335.0 \pm 28.52^{* * *}(+77 \%)$ & $169.9 \pm 15.09^{\text {ns }}$ & $211.7 \pm 9.409^{\mathrm{ns}}$ & $227.7 \pm 13.41^{*}$ \\
\hline $\mathrm{HDL}^{\mathrm{a}}$ & $39.69 \pm 5.41$ & $25.54 \pm 2.17^{* * *}(-35 \%)$ & $14.98 \pm 3.04^{* * *}(-64 \%)$ & $41.12 \pm 2.67^{\mathrm{ns}}$ & $33.54 \pm 2.78^{\mathrm{ns}}$ & $32.14 \pm 2.10^{*}$ \\
\hline
\end{tabular}

${ }^{a} \mathrm{mg} \mathrm{dL}^{-1}$; the (-) and (+) signs show decrease and increase, respectively, in the levels of cholesterol and HDL. The values are mean \pm SD of five independent experiments. The procedures for estimation of the activities of the enzymes were as mentioned in Section $2 *$ and $* * *$ indicate the $P$ values significance at $<0.05$ and $<0.001$, respectively. ns: nonsignificant at $P>0.05$ as compared to control.

the alterations in the levels of total cholesterol and HDL in the serum due to carbofuran treatment. The pesticide at low concentration $\left(5 \% \mathrm{LD}_{50}\right)$ was found to significantly increase the levels of total cholesterol by $47 \%$, which further increased to $77 \%$ at higher concentration $\left(10 \% \mathrm{LD}_{50}\right)$. In contrast, the levels of HDL were observed to be sharply decreased. The extent of reduction in HDL level was 35 and 64\%, respectively, at 5 and $10 \% \mathrm{LD}_{50}$ of carbofuran. The levels of total cholesterol and HDL were also monitored in the serum from those rats which were pretreated with vitamin $C$. The data presented in Table 6 indicated that vitamin C could help restore their levels significantly as their values were recovered close to that of the control (Table 6).

\section{Discussion}

The chronic and acute impact of carbofuran on the key tissues of mammalian systems such as liver [5] and kidney [17], nerve cells [10], and erythrocytes of humans [32] have been studied using subacute doses of the pesticide. According to one report from Tonomura et al. (2009) [33], the treatment of rat with a single subacute dose of carbofuran caused sharp variations in the levels of certain biomarkers of the heart such as activities of LDH and creatinine kinase as well as the level of troponin T. However, only limited information is available regarding the assessment of carbofuran toxicity in the mammalian heart after prolonged exposure of the experimental animal to carbofuran. Therefore, in the present study, an endeavour was made to evaluate the impact of carbofuran by exposing the rats to two subacute doses of the compound equivalent to 5 and $10 \% \mathrm{LD}_{50}$ at the interval of $24 \mathrm{~h}$ up to one month. Possibly, this is the first study of its kind to report carbofuran induced oxidative stress in the heart of a rat upon exposure of the experimental animal to two different subacute concentrations of the compound up to 30 days and the assessment of the ameliorative potential of vitamin $\mathrm{C}$ therein.

The AChE is a membrane-bound enzyme which catalyses the hydrolysis of acetylcholine (ACh) at cholinergic nerve terminals. The inhibition of AChE by carbofuran is known 
to serve as a positive control. The results of the present study demonstrated that the subacute concentrations of carbofuran were able to sharply reduce the activity of AChE in the rat heart tissues. The extent of enzyme inhibition exhibited positive correlation with the concentration of the tested carbofuran. The inhibition of AChE activity from mammalian cardiac tissues by carbofuran has not been reported by any other worker. However, the inhibition of AChE in the rat heart by an organophosphate group of pesticide, diazinon, has been shown [34]. Apart from the heart, the AChE activity in the rat brain has been demonstrated by oral application of single subacute dose of carbofuran [10].

Though the LDH is not the direct target of action by carbofuran, some workers have reported reduction in the activity of $\mathrm{LDH}$ in rat heart tissues due to the exposure of the experimental animal to single subacute dose of this compound [33]. In the present study, the prolonged exposure of rat up to 30 days to two different subacute doses of carbofuran also resulted in sharp decline in the enzyme activity in the heart of the rat. Similar to these observations, Gupta et al. [35] have shown that carbofuran at acute concentration was able to cause perturbations in the pattern of LDH isozymes in the target tissues of rat. The mechanism of action of carbofuran at the level of $\mathrm{LDH}$, however, is not clearly known yet.

In contrast to the impact of carbofuran on LDH activity in the rat heart tissues, a sharp increase in the activity of this enzyme was recorded in the serum, which indicates the damage of cardiac cell membranes resulted in leakage of this enzyme in rat blood serum under the experimental conditions of the present study. Suggesting LDH as a cardiac biomarker, Tonomura et al. [33] have also reported similar results by exposing the rat to single subacute dose of carbofuran.

The increase in the basal levels of MDA and nonenzymatic antioxidants such as total thiols and GSH is considered the onset of oxidative stress in animal systems exposed to any xenobiotics. The underlying mechanism of pesticide toxicity is believed to be via generation of free radicals and production of oxidative stress. The results from the present study have demonstrated that the treatment of rats with subacute doses of carbofuran for prolonged period (30 days) caused significant elevation in the levels of MDA, total thiols, and GSH, suggesting, thereby, the generation of carbofuran induced oxidative stress in the cardiac tissues. With other pesticides such as diazinon $[34,36]$ and lindane [37] similar results have been reported in the cardiac tissues.

The available information indicates that the inhibition in AChE activity due to action of carbofuran causes increase in ACh concentration at the synaptic junctions. It develops hyperexcitation resulting in increase in the flow of oxygen and consumption of ATP in the muscle and brain than its production. This metabolic stress in tissue causes generation of oxidative stress due to overproduction of reactive oxygen species $[2,10]$. The polyunsaturated fatty acids undergo lipid peroxidation (LPO) by reactive oxygen species (ROS) under stress condition and the end product of it is MDA [38]. The increase in the level of MDA indicates the increased level of oxidative stress induced by the toxicant in the key tissues of the body such as brain, liver, heart, and other organs and plasma membrane of RBCs [5, 14, 36, 39, 40]. Carbofuran has also been shown to induce oxidative stress in the skeletal muscles due to increased generation of reactive oxygen and nitrogen species [41]. Some workers have speculated that the enhancement in the generation of reactive oxygen species by carbofuran may be due to the inhibition of cytochrome c oxidase and creatine kinase [42-44]. Also, the carbofuran induced nitic oxide synthase activity has been implicated in the overproduction of superoxide anions [45].

Glutathion is a tripeptide which eliminates reactive oxygen (ROS) and nitrogen species (RNS) produced during normal physiological activities and/or during oxidative stress $[46,47]$. The results from the present investigation demonstrate the significant increase in the level of GSH in the heart due to prolonged exposure to carbofuran as compared to control group animals. Under this condition, the increased level of GSH in cardiac muscles may contribute to improve the antioxidant defense mechanism evolved by the animal system to protect it from the damage caused by free radicalmediated oxidative stress. These results corroborate with that reported in the kidney of rat exposed to carbofuran for 28 days at $1 \mathrm{mg} \mathrm{kg}^{-1}$ body weight [17]. In contrast to these findings, the level of GSH in rat liver has been reported to be drastically reduced after acute exposure to carbofuran [5]. The lindane treatment also caused decrease in the level of GSH in cardiac tissues of the rat [37].

The antioxidant enzymes such as SOD, catalase, and GST are best characterized by their first line of defense against oxidative stress as they are believed to maintain balance between the production of reactive oxygen species and antioxidant defense system as a consequence of oxidative stress [48]. The damage due to superoxide anion is controlled by SOD which catalyses the conversion of superoxide anion into nontoxic molecular oxygen and toxic $\mathrm{H}_{2} \mathrm{O}_{2}$. Further the toxic $\mathrm{H}_{2} \mathrm{O}_{2}$ gets converted into nontoxic molecules such as water and molecular $\mathrm{O}_{2}$ [49]. In the present study, the significant decrease in the levels of these antioxidant enzymes due to prolonged exposure to carbofuran indicates the onset of carbofuran induced oxidative stress in the rat heart tissues. The reduction in the inhibition of enzymatic antioxidants demonstrated the failure of antioxidant system, which may result in cardiac toxicity. Similar observations have been made in kidney of rat due to its chronic exposure to the same pesticide $[5,17]$. Another organocarbamate pesticide, methiocarb, also causes reduction in the activities of SOD and catalase in liver and kidney of rats [50], which may be responsible for generation of superoxide radicals [51]. In contrast to these observations, the single subacute dose of carbofuran in the rats showed elevation in the activities of SOD and catalase in brain [16] and erythrocytes [9]. The elevated activities of SOD and catalase have been described to be associated with the adaptive mechanism of the antioxidative defense system. Other pesticides such as lindane (an organochlorine) [37] and fenitrothion (an organophosphate) [52] have been reported to induce the activities of SOD and catalase in cardiac and liver tissues, respectively.

The estimates of HDL and cholesterol in blood serum have been used by many workers as potential biomarkers to 
assess the health status of heart. The serum lipid alterations act as indicator of cardiac dysfunction. The increase in the level of cholesterol and decrease in the level of HDL in the blood serum as observed in the present study indicate carbofuran induced perturbations in the heart of the experimental animal. The data corroborate with the results reported by Rai et al. [53] in rat exposed to subacute concentrations of carbofuran and cartap for 7 days. Similarly, in another study with sodium arsenite, significant increase of total cholesterol in serum was obtained [54].

Vitamin C, a potential antioxidant, has been shown to reduce the load of free radicals by neutralising these highly reactive chemical species via oxygen scavenging, hydroperoxide reduction, and stabilization of free radicals into neutral and nontoxic chemicals [55]. The carbofuran induced oxidative stress in rats in the present study in terms of rise in the levels of MDA, GSH, and total thiols was found to be reduced to near normal level upon pretreatment of the experimental animals with vitamin $\mathrm{C}\left(100 \mathrm{mg} \mathrm{kg}^{-1}\right.$ body weight) or the level of oxidative stress. Vitamin C treatment was also observed to ameliorate the altered levels of SOD, catalase, and GST in the heart tissues of rat exposed to carbofuran. The results of the present study are in conformity with those reported by other workers $[9,56]$. The ameliorative effect of vitamin C has also been demonstrated by Rai et al. [10] with membranebound AChE of RBC from rat exposed to carbofuran as well as in the rat kidney intoxicated with another group of pesticide, lambda-cyhalothrin [20]. In another in vitro study with treatment of human RBCs with vitamin C followed by exposure to varying concentrations of carbofuran, the protection from pesticide mediated genotoxicity has been shown via reduction in oxidative stress [18].

\section{Conclusion}

The results of the present work have indicated that carbofuran was able to generate oxidative stress in rat heart tissues at two different subacute concentrations when treated for 30 days at the interval of $24 \mathrm{~h}$. It caused elevation in the levels of MDA, total thiols, and GSH in heart tissues. It also reduced the activities of SOD, catalase, and GST which would have contributed in rise into the level of oxidative stress. The carbofuran mediated inhibition in the activities of AChE and LDH indicated the impact of the pesticide on the nerve impulse transmission and energy generation systems in the heart. The increased level of LDH activity in rat blood serum indicated leakage of this enzyme due to damage of cardiac cells. The increase in cholesterol and decrease in HDL in rat blood serum indicated adverse impact of carbofuran in rat heart tissues. The pretreatment of rats with vitamin $\mathrm{C}$ followed by exposure to carbofuran suggested its ameliorative potential as it could reduce the oxidative stress and help recovery the aforesaid parameters to near control values. The results from the present study reflect that vitamin C could be utilized as an effective supplement in appropriate management of pesticide toxicity.

\section{Conflict of Interests}

The authors declare that they do not have any conflict of interests.

\section{Acknowledgments}

The author Sunil Kumar Jaiswal is grateful to University Grants Commission (UGC), New Delhi, for the financial support in the form of a fellowship. Nikhat J. Siddiqi would like to thank the Research Center, Center for Scientific and Medical Female Colleges, King Saud University, Riyadh, for the financial support.

\section{References}

[1] D. Milatovic, R. C. Gupta, and M. Aschner, "Anticholinesterase toxicity and oxidative stress," TheScientificWorldJournal, vol. 6, pp. 295-310, 2006.

[2] A. Agrawal and B. Sharma, "Pesticides induced oxidative stress in mammalian systems: a review," International Journal of Biological and Medical Research, vol. 1, no. 3, pp. 90-104, 2010.

[3] R. K. Loch-Caruso, K. A. Criswell, C. M. Grindatti, and K. A. Brant, "Sustained inhibition of rat myometrial gap junctions and contractions by lindane," Reproductive Biology and Endocrinology, vol. 1, p. 62, 2003.

[4] M. Sauviat, A. Colas, and N. Pages, "Does lindane (gammahexachlorocyclohexane) increase the rapid delayed rectifier outward $\mathrm{K}+$ current (IKr) in frog atrial myocytes?" BMC Pharmacology, vol. 2, p. 15, 2002.

[5] M. Kaur and R. Sandhir, "Comparative effects of acute and chronic carbofuran exposure on oxidative stress and drugmetabolizing enzymes in liver," Drug and Chemical Toxicology, vol. 29, no. 4, pp. 415-421, 2006.

[6] R. C. Gupta, "Carbofuran toxicity, Journal of Toxicology and Environmental Health, vol. 43, no. 4, pp. 383-418, 1994.

[7] J. Rendón-Von Osten, A. M. V. M. Soares, and L. Guilhermino, "Black-bellied whistling duck (Dendrocygna autumnalis) brain cholinesterase characterization and diagnosis of anticholinesterase pesticide exposure in wild populations from Mexico," Environmental Toxicology and Chemistry, vol. 24, no. 2, pp. 313-317, 2005.

[8] R. M. Whyatt, D. B. Barr, D. E. Camann et al., "Contemporaryuse pesticide in personal air samples during pregnancy and blood samples at delivery among urban minority mothers and newborns," Environmental Health Perspectives, vol. 111, no. 5, pp. 749-756, 2003.

[9] D. K. Rai, P. K. Rai, S. I. Rizvi, G. Watal, and B. Sharma, "Carbofuran-induced toxicity in rats: protective role of vitamin C," Experimental and Toxicologic Pathology, vol. 61, no. 6, pp. 531-535, 2009.

[10] D. K. Rai, R. K. Sharma, P. K. Rai, G. Watal, and B. Sharma, "Role of aqueous extract of Cynodon dactylon in prevention of carbofuran-induced oxidative stress and acetylcholinesterase inhibition in rat brain," Cellular and Molecular Biology, vol. 57, no. 1, pp. 135-142, 2011.

[11] Z. P. Yang and W. Dettbarn, "Diisopropylphosphorofluoridateinduced cholinergic hyperactivity and lipid peroxidation," Toxicology and Applied Pharmacology, vol. 138, no. 1, pp. 48-53, 1996. 
[12] J. N. Keller, R. J. Mark, A. J. Bruce et al., "4-hydroxynonenal, an aldehydic product of membrane lipid peroxidation, impairs glutamate transport and mitochondrial function in synaptosomes," Neuroscience, vol. 80, no. 3, pp. 685-696, 1997.

[13] R. J. Mark, Z. Pang, J. W. Geddes, K. Uchida, and M. P. Mattson, "Amyloid $\beta$-peptide impairs glucose transport in hippocampal and cortical neurons: involvement of membrane lipid peroxidation," Journal of Neuroscience, vol. 17, no. 3, pp. 1046-1054, 1997.

[14] A. Kamboj, R. Kiran, and R. Sandhir, "N-Acetylcysteine ameliorates carbofuraninduced alterations in lipid composition and activity of membrane bound enzymes," Molecular and Cellular Biochemistry, vol. 286, no. 1-2, pp. 107-114, 2006.

[15] S. Padilla, R. S. Marshall, D. L. Hunter, and A. Lowit, "Time course of cholinesterase inhibition in adult rats treated acutely with carbaryl, carbofuran, formetanate, methomyl, methiocarb, oxamyl or propoxur," Toxicology and Applied Pharmacology, vol. 219, no. 2-3, pp. 202-209, 2007.

[16] D. K. Rai and B. Sharma, "Carbofuran-induced oxidative stress in mammalian brain," Molecular Biotechnology, vol. 37, no. 1, pp. 66-71, 2007.

[17] B. Kaur, A. Khera, and R. Sandhir, "Attenuation of cellular antioxidant defense mechanisms in kidney of rats intoxicated with carbofuran," Journal of Biochemical and Molecular Toxicology, vol. 26, no. 10, pp. 393-398, 2012.

[18] R. K. Sharma and B. Sharma, "In-Vitro carbofuran induced genotoxicity in human lymphocytes and its mitigation by vitamins C and E," Disease Markers, vol. 32, no. 3, pp. 153-163, 2012.

[19] S. Srinivasan and L. Pari, "Ameliorative effect of diosmin, a citrus flavonoid against streptozotocin-nicotinamide generated oxidative stress induced diabetic rats," Chemico-Biological Interactions, vol. 195, no. 1, pp. 43-51, 2012.

[20] H. Fetoui, M. Makni, E. Mouldi Garoui, and N. Zeghal, "Toxic effects of lambda-cyhalothrin, a synthetic pyrethroid pesticide, on the rat kidney: involvement of oxidative stress and protective role of ascorbic acid," Experimental and Toxicologic Pathology, vol. 62, no. 6, pp. 593-599, 2010.

[21] J. H. Doroshow, G. Y. Locker, and C. E. Myers, "Enzymatic defenses of the mouse heart against reactive oxygen metabolites. Alterations produced by doxorubicin," Journal of Clinical Investigation, vol. 65, no. 1, pp. 128-135, 1980.

[22] G. L. Ellman, K. D. Courtney, V. Andres Jr., and R. M. Featherstone, "A new and rapid colorimetric determination of acetylcholinesterase activity," Biochemical Pharmacology, vol. 7, no. 2, pp. 88-95, 1961.

[23] B. L. Horecker and A. Kornberg, "The extinction coefficient of the reduced band of pyridine nucleotides," Journal of Biological Chemistry, vol. 175, pp. 385-390, 1948.

[24] A. Zlatkis, B. Zak, and A. J. Boyle, "A new method for the direct determination of serum cholesterol," The Journal of Laboratory and Clinical Medicine, vol. 41, no. 3, pp. 486-492, 1953.

[25] M. F. Lopes Virella, P. Stone, S. Ellis, and J. A. Colwell, "Cholesterol determination in high density lipoproteins separated by three different methods," Clinical Chemistry, vol. 23, no. 5, pp. 882-884, 1977.

[26] W. G. Niehaus Jr. and B. Samuelsson, "Formation of malonaldehyde from phospholipid arachidonate during microsomal lipid peroxidation," European Journal of Biochemistry, vol. 6, no. 1, pp. 126-130, 1968.
[27] S. Marklund and G. Marklund, "Involvement of the superoxide anion radical in the autoxidation of pyrogallol and a convenient assay for superoxide dismutase," European Journal of Biochemistry, vol. 47, no. 3, pp. 469-474, 1974.

[28] R. F. Beers Jr. and I. W. Sizer, "A spectrophotometric method for measuring the breakdown of hydrogen peroxide by catalase," The Journal of Biological Chemistry, vol. 195, no. 1, pp. 133-140, 1952.

[29] W. H. Habig, M. J. Pabst, and W. B. Jakoby, "Glutathione $S$ transferases. The first enzymatic step in mercapturic acid formation," Journal of Biological Chemistry, vol. 249, no. 22, pp. 7130-7139, 1974.

[30] J. Sedlak and R. H. Lindsay, "Estimation of total, proteinbound, and nonprotein sulfhydryl groups in tissue with Ellman's reagent," Analytical Biochemistry C, vol. 25, pp. 192-205, 1968.

[31] O. H. Lowry, N. J. Rosebrough, A. L. Farr, and R. J. Randel, "Protein measurement with the Folin phenol reagent," The Journal of Biological Chemistry, vol. 193, no. 1, pp. 265-275, 1951.

[32] R. K. Sharma, S. K. Jaiswal, N. J. Siddiqi, and B. Sharma, "Effect of carbofuran on some biochemical indices of human erythrocytes in vitro," Cellular \& Molecular Biology, vol. 58, no. 1, pp. 103-109, 2012.

[33] Y. Tonomura, Y. Mori, M. Torii, and T. Uehara, "Evaluation of the usefulness of biomarkers for cardiac and skeletal myotoxicity in rats," Toxicology, vol. 266, no. 1-3, pp. 48-54, 2009.

[34] B. M. Razavi, H. Hosseinzadeh, A. R. Movassaghi, M. Imenshahidi, and K. Abnous, "Protective effect of crocin on diazinon induced cardiotoxicity in rats in subchronic exposure," Chemico-Biological Interaction, vol. 203, no. 3, pp. 547-555, 2013.

[35] R. C. Gupta, J. T. Goad, and W. L. Kadel, "In vivo alterations in lactate dehydrogenase $(\mathrm{LDH})$ and $\mathrm{LDH}$ isoenzymes patterns by acute carbofuran intoxication," Archives of Environmental Contamination and Toxicology, vol. 21, no. 2, pp. 263-269, 1991.

[36] A. Ogutcu, M. Uzunhisarcikli, S. Kalender, D. Durak, F. Bayrakdar, and Y. Kalender, "The effects of organophosphate insecticide diazinon on malondialdehyde levels and myocardial cells in rat heart tissue and protective role of vitamin E," Pesticide Biochemistry and Physiology, vol. 86, no. 2, pp. 93-98, 2006.

[37] R. Ananya, S. Subeena, D. A. Kumar, D. T. Kumar, and M. S. Kumar, "Oxidative stress and histopathological changes in the heart following oral lindane (gamma hexachlorohexane) administration in rats," Medical Science Monitor, vol. 11, no. 9, pp. BR325-BR329, 2005.

[38] I. A. Zervos, E. Nikolaidis, S. N. Lavrentiadou et al., "Endosulfan-induced lipid peroxidation in rat brain and its effect on t-PA and PAI-1:Ameliorating effect of vitamins C and E," Journal of Toxicological Sciences, vol. 36, no. 4, pp. 423-433, 2011.

[39] D. S. Cassarino and J. P. Bennett Jr., "An evaluation of the role of mitochondria in neurodegenerative diseases: mitochondrial mutations and oxidative pathology, protective nuclear responses, and cell death in neurodegeneration," Brain Research Reviews, vol. 29, no. 1, pp. 1-25, 1999.

[40] T. Yavuz, N. Delibas, B. Yildirim et al., "Vascular wall damage in rats induced by organophosphorus insecticide methidathion," Toxicology Letters, vol. 155, no. 1, pp. 59-64, 2005.

[41] D. Milatovic, R. C. Gupta, A. Dekundy, T. J. Montine, and W. Dettbarn, "Carbofuran-induced oxidative stress in slow and fast skeletal muscles: prevention by memantine and atropine," Toxicology, vol. 208, no. 1, pp. 13-24, 2005. 
[42] D. Milatovic, M. Zivin, R. C. Gupta, and W. Dettbarn, "Alterations in cytochrome c oxidase activity and energy metabolites in response to kainic acid-induced status epilepticus," Brain Research, vol. 912, no. 1, pp. 67-78, 2001.

[43] R. C. Gupta, D. Milatovic, and W. D. Dettbarn, "Nitric oxide modulates high-energy phosphates in brain regions of rats intoxicated with diisopropylphosphorofluoridate or carbofuran: prevention by N-tert-butyl- $\alpha$-phenylnitrone or vitamin E," Archives of Toxicology, vol. 75, no. 6, pp. 346-356, 2001.

[44] M. Brunori, A. Giuffrè, P. Sarti, G. Stubauer, and M. T. Wilson, "Nitric oxide and cellular respiration," Cellular and Molecular Life Sciences, vol. 56, no. 7-8, pp. 549-557, 1999.

[45] S. Pou, W. S. Pou, D. S. Bredt, S. H. Snyder, and G. M. Rosen, "Generation of superoxide by purified brain nitric oxide synthase," Journal of Biological Chemistry, vol. 267, no. 34, pp. 24173-24176, 1992.

[46] V. I. Lushchak, "Glutathione homeostasis and functions: potential targets for medical interventions," Amino Acids, vol. 2012, Article ID 736837, 26 pages, 2012.

[47] H. Sies, "Glutathione and its role in cellular functions," Free Radical Biology and Medicine, vol. 27, no. 9-10, pp. 916-921, 1999.

[48] R. Dringen, "Metabolism and functions of glutathione in brain," Progress in Neurobiology, vol. 62, no. 6, pp. 649-671, 2000.

[49] B. Halliwell, "Reactive oxygen species and the central nervous system," Journal of Neurochemistry, vol. 59, no. 5, pp. 1609-1623, 1992.

[50] S. Ozden and B. Alpertunga, "Effects of methiocarb on lipid peroxidation and glutathione level in rat tissues," Drug and Chemical Toxicology, vol. 33, no. 1, pp. 50-54, 2010.

[51] B. D. Goldstein, M. G. Rozen, J. C. Quintavalla, and M. A. Amoruso, "Decrease in mouse lung and liver glutathione peroxidase activity and potentiation of the lethal effects of ozone and paraquat by the superoxide dismutase inhibitor diethyldithio-carbamate," Biochemical Pharmacology, vol. 28, no. 1, pp. 27-30, 1979.

[52] F. M. El-Demerdash, "Oxidative stress and hepatotoxicity induced by synthetic pyrethroids-organophosphate insecticides mixture in rat," Journal of Environmental Science and Health $C$, vol. 29, no. 2, pp. 145-158, 2011.

[53] D. K. Rai, P. K. Rai, A. Gupta, G. Watal, and B. Sharma, "Cartap and carbofuran induced alterations in serum lipid profile of Wistar rats," Indian Journal of Clinical Biochemistry, vol. 24, no. 2, pp. 198-201, 2009.

[54] M. I. Yousef, F. M. El-Demerdash, and F. M. E. Radwan, "Sodium arsenite induced biochemical perturbations in rats: ameliorating effect of curcumin," Food and Chemical Toxicology, vol. 46, no. 11, pp. 3506-3511, 2008.

[55] E. N. Frankel, "Antioxidants in lipid foods and their impact on food quality," Food Chemistry, vol. 57, no. 1, pp. 51-55, 1996.

[56] D. Chandra, U. N. Tripathi, S. Srivastava, and A. Swaroop, "Carbofuran induced biochemical toxicity in mice: protective role of Momordica charantia," European Journal of Experimental Biology, vol. 1, no. 1, pp. 106-112, 2011. 


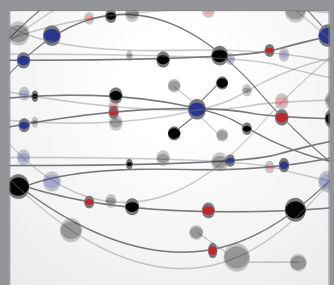

The Scientific World Journal
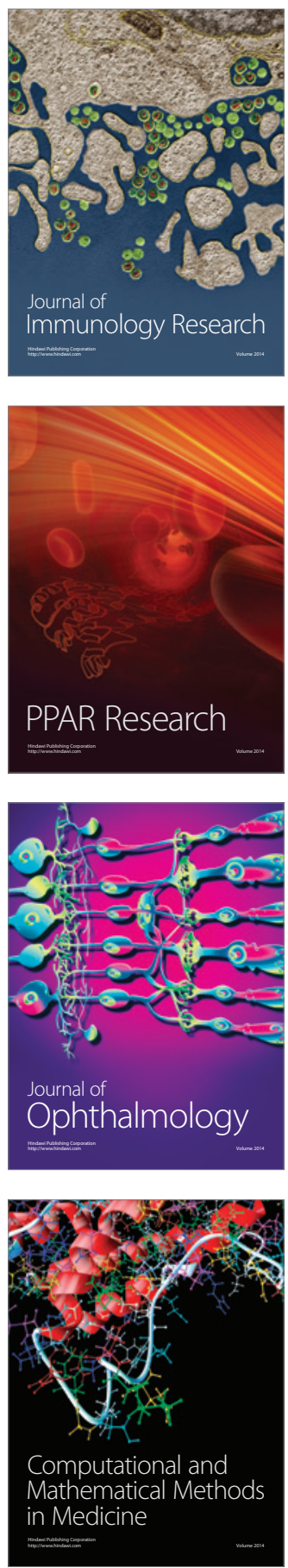

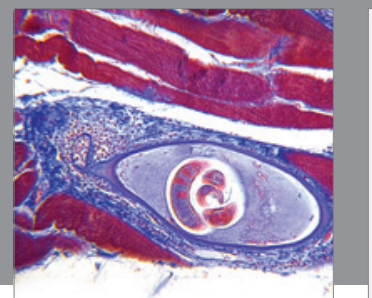

Gastroenterology

Research and Practice
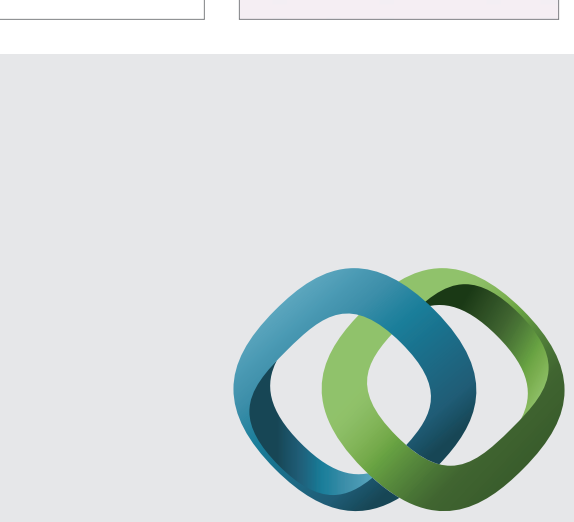

\section{Hindawi}

Submit your manuscripts at

http://www.hindawi.com
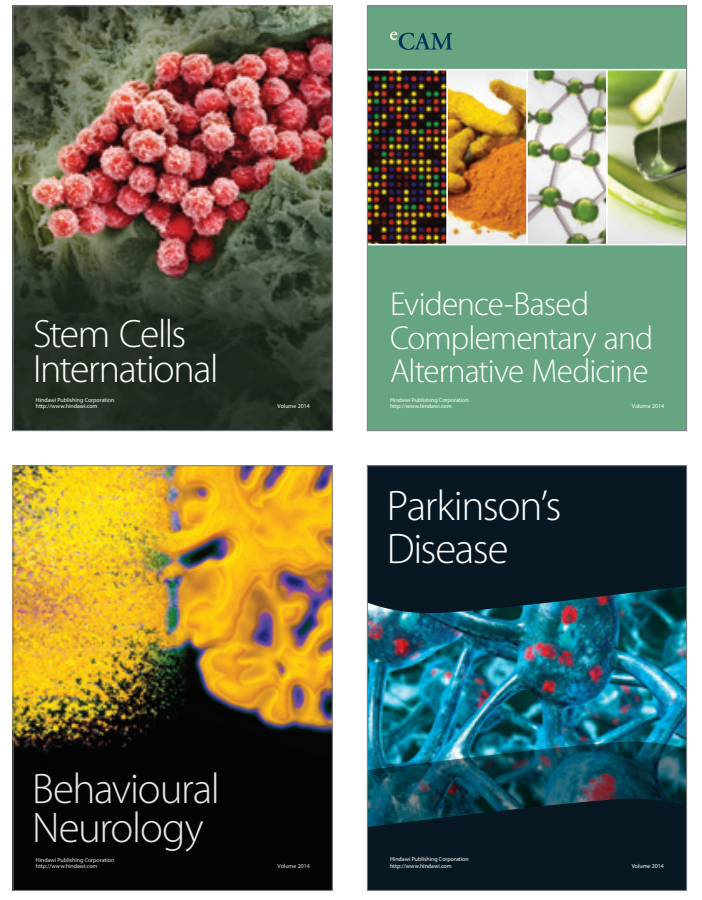
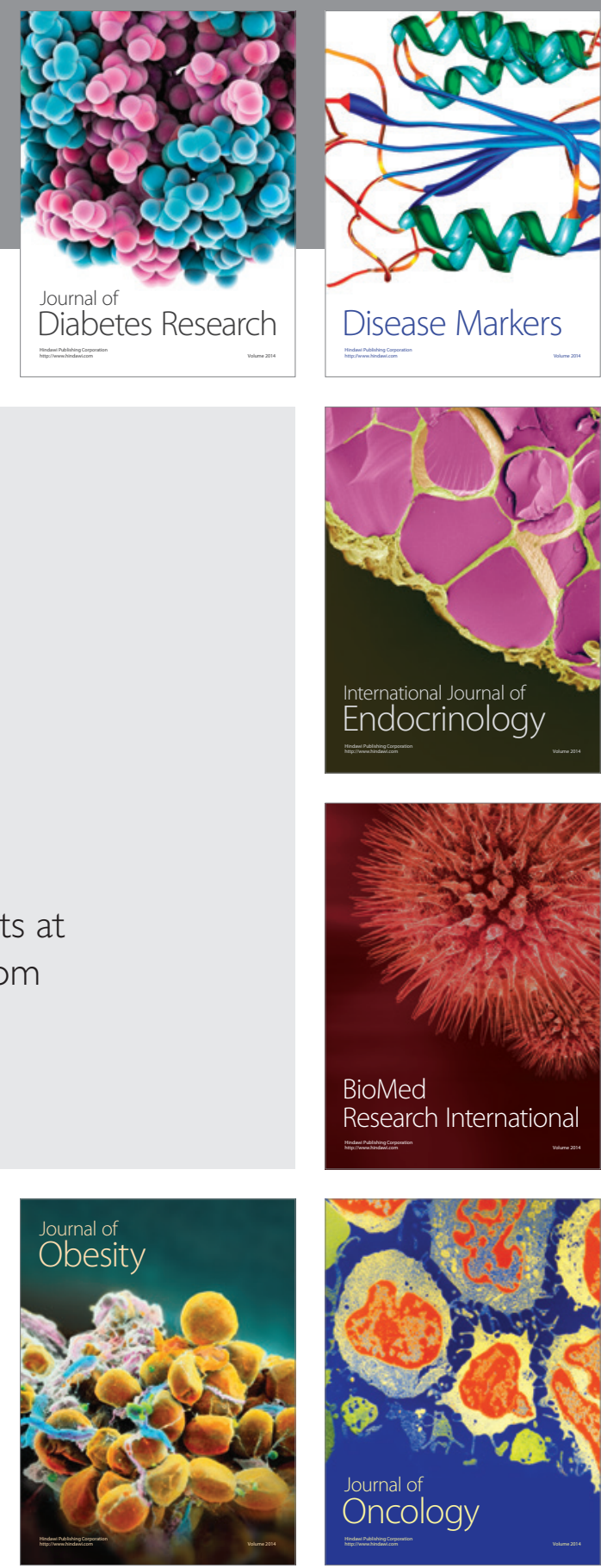

Disease Markers
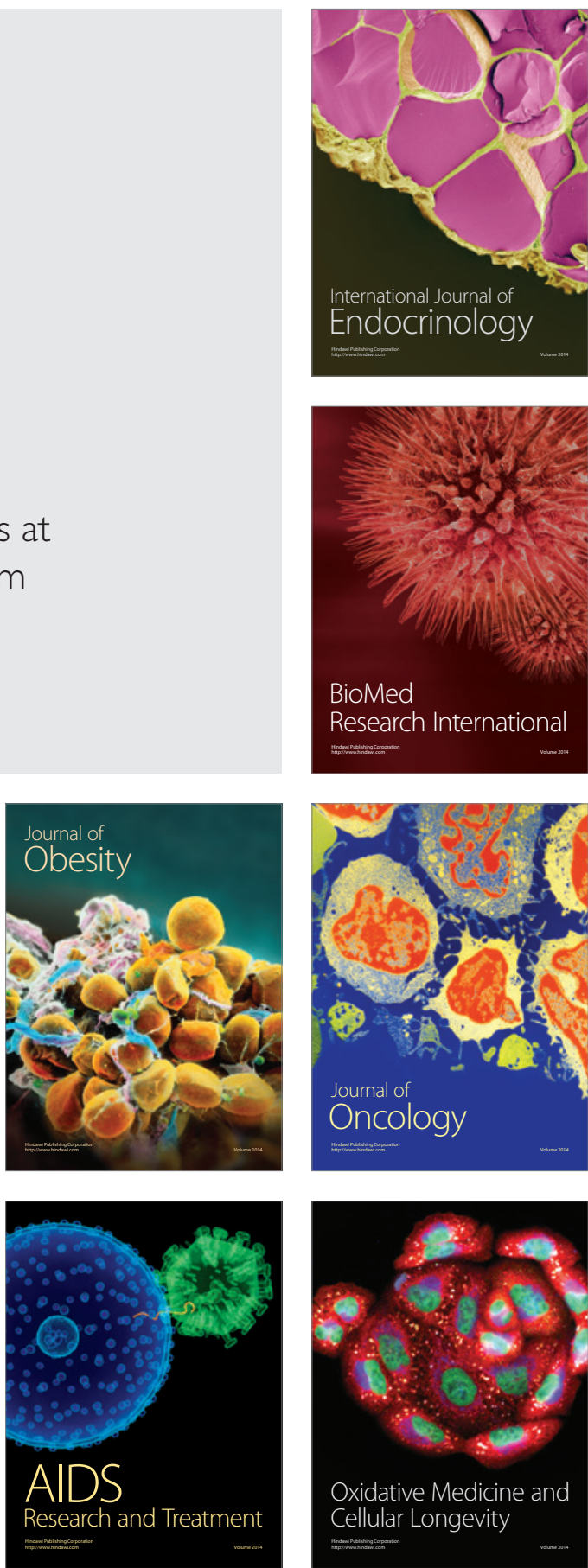